\section{A Tutorial for Modeling Real Options Lattices from Project Cash Flows}

\author{
Tutorial para a Modelagem de Malha Binomial de Opções Reais a partir do \\ Fluxo de Caixa de Projetos
}

\author{
Tuxo de Caxa de Projetos
}

\title{
m
}




\section{INTRODUCTION}

Real options approach (ROA) was developed to overcome the limitations of the discounted cash flow method by using option-pricing methods to capture the value of any managerial flexibility that may be embedded in a project subject to future uncertainty.

It is a well-established principle in Finance and Economics that the correct measure of an asset are the future cash flows it generates, discounted to the present time at an appropriate risk-adjusted rate. Nevertheless, in the case of real assets, this principle does not account for the uncertainty over the future behavior of the cash flows nor for the value generated by the flexibility some projects have to react to future events. In order to value project cash flows which can flexibly change their trajectory, as future uncertainties are resolved, it is necessary to use a more adequate approach. Given that the flexibility to adapt to changes in expected future cash flows has option-like characteristics, they can only be valued with option-pricing methods.

The real options approach fulfills these conditions and has been widely discussed in the academic and practitioner literature. Although several option-pricing methods are well known and widely used, probably the most intuitive and flexible method is the binomial lattice option-pricing model originally developed by Cox, Ross and Rubinstein (1979)for financial options (CRR model) and then extended by Copeland and Antikarov (2001) for the pricing of real options.

However, even though the CRR binomial lattice model is widely used in the real options literature (Ashuri, Kashani, Molenaar, Lee, \& Lu, 2012; Bastian-Pinto, Brandão, \& Hahn, 2009; Brandão \& Dyer, 2005; Jang, Lee, \& Oh, 2013; Kim, Park, \& Kim, 2017; Lee \& Shih, 2010; Lin \& Wesseh, 2013), there are many obstacles and difficulties in its implementation for real options valuation, as its principles are sometimes not very well understood by practitioners. In this tutorial, we guide the user through the sequence of steps necessary for the correct implementation of a real options model based on project cash flow estimation.

We begin by explaining the simplest CRR binomial model and its parameters, showing a direct application with the corresponding $\mathrm{R}$ code for a simple application of option valuation. Then we explain the issues and characteristics of a project cash flow model and show how to implement the CRR approach in such a model. We do that by demonstrating the procedure required to correctly estimate the volatility of the project value $(V)$ from the project uncertainties. Next, we show how to incorporate the project cash flows into the CRR lattice using the cash flow dividend rate, as suggested by Copeland and Antikarov (2001), to create the value lattice of the project. Following that, we show how to model the project flexibilities, or real options, as decision nodes in the project value lattice, and determine the expanded value of the project with a backward maximization framework. Finally, we develop an additional $R$ language code specifically to run this model and provide a detailed step-by-step tutorial on parameter determination and use of the model, showing how the code can be customized for particular applications.

\section{VALUING DERIVATIVES WITH THE CRR LATTICE MODEL}

Financial options are classified as derivative securities since their value derives in part from the price of another marketed financial asset, known as the underlying asset.

The Cox, Ross and Rubinstein (1979) binomial tree, or lattice model, emulates the Black and Sholes (1973) (B\&S) option valuation approach. One advantage of this model is that it allows for the pricing of American type options, which can be exercised at any time before expiration, which is not possible under the B\&S model. Although it is a discrete approach, it is accurate enough for most real asset valuation applications.

To implement the CRR model on a derivative of an asset whose current price is $S_{0}$, and has a volatility of $\sigma$, at each time step the asset value $(S)$ is multiplied by a random variable that can take two values, $u$ or $d$. For this representation to emulate a lognormal distribution, the values for $u$ and $d$ and the risk neutral probability $p$ must be as shown in equations (1) where $\sigma$ is the asset volatility and $r$ is the risk-free discount rate.

$$
u=e^{\sigma \sqrt{\Delta t}}, d=\frac{1}{u}, \text { and } p=\frac{(1+r)^{\Delta t}-d}{u-d}
$$

where $u$ and $d$ are respectively the up and down multipliers of the lattice nodes, and $p$ is the risk-neutral probability, which will be used in discounting the lattice nodes.

With these parameters, we can implement the lattice shown in Figure 1, which is a discretization of a geometric Brownian motion (GBM) diffusion process for $S$. In the last period $n$, which is the time of expiration of the option or last period of the lattice, the options, which are a maximization process, are exercised on the values of $S n$ at each node. At the nodes where the options are exercised, the values of $S n$ change to $S_{n}^{\prime}$. These can be call options or put options. After this step, we move to the previous period $(n-1)$ and perform the same maximization process at each node, but now also considering the value of continuation, which takes in account the present value of the expected future nodes discounted at the risk-free rate and weighted by the probabilities $p$ and $(1-p)$. 


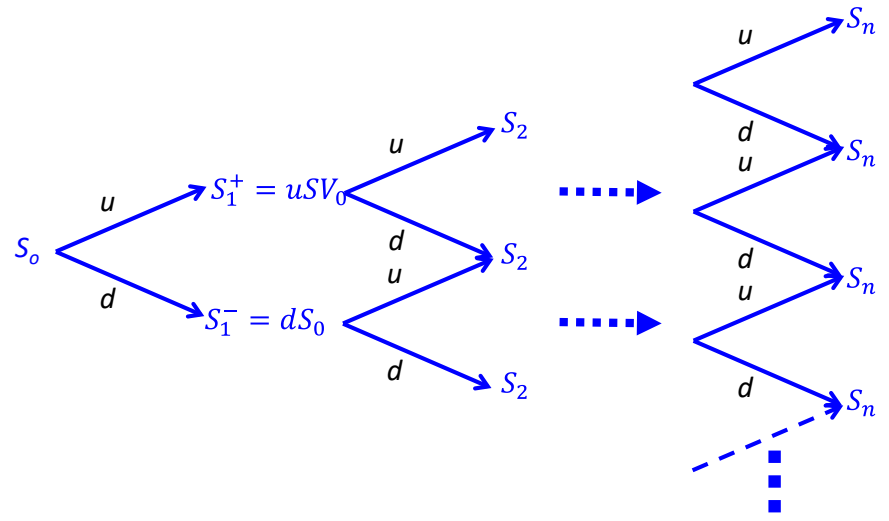

Figure 1. The CRR binomial lattice model.

Source: Cox, J. C., Ross, S. A., \& Rubinstein, M. (1979). Option pricing: A simplified approach. Journal of Financial Economics, 7(3), 229-263. https://doi.org/10.1016/0304-405X(79)90015-1.

This is a discretization of a geometric Brownian motion (GBM) diffusion process for price $S$ using the volatility $\sigma$ of this price through the multipliers $u$ and $d$ from equation (1). The recombining feature of the lattice is important since at the final step $n$, it will have $n+1$ nodes, instead of $2^{n}$ in the case of a non-recombining tree.

This process of backward maximization is summarized by equation (2).

$$
\operatorname{maximum}\left[S_{t-1}^{\prime} ;\left(S_{t}^{\prime+} p+S_{t}^{\prime-}(1-p)\right) /(1+r)\right]
$$

where $S_{t}$ is the asset value at time $t$, before the exercise of any option, and of $S_{t}^{\prime}$ after the exercise of an option.

The whole process is shown in Figure 2, where at the initial step, the bold red arrow indicates the value of the options exercised along the whole lattice.

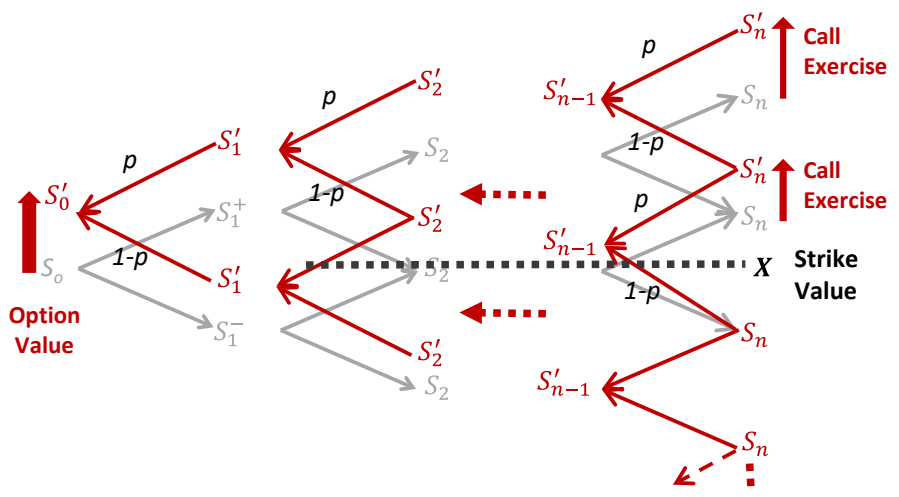

Figure 2. Diagram showing backward discounting of the CRR lattice for a call option.

This figure shows that the call option is exercised above the strike value $X$. Starting from the last period $n$ after exercising the options, we move backward at each node, weighting the future values by the risk neutral probabilities $p$ and $(1-p)$ and discounting with the risk-free rate $r$ using equation (2), up to the initial step.

In order to help researchers and practitioners understand how this CRR binomial model works for the calculation of financial options, we provide a simple code with the open software R (www.r-project.org, retrieved in March 20, 2020), which uses the available fOptions package developed by Wuertz, Setz and Chalabi (2017). This code, available online, evaluates call and put options considering the following parameters: $n=1.5$ years (18 months); $S_{0}=\$ 100 ; \sigma=30 \%$ per year; $r=6 \%$ per year; call strike price of $\$ 120$; and put strike price of $\$ 90$. After running this code, considering $d t=2$ months, we find that the call value is $\$ 11.00$ and the put value is $\$ 6.71$.

Note that the fOptions package is very well suited for this type of calculation and for plotting the binomial lattices. However, it does not allow us to determine the value of the real options, whose main characteristics are having investment projects as underlying assets and more complex exercise rules. Given this, we develop in this article a specific $\mathrm{R}$ code for modeling real options applications based on project cash flows. This code is described in section "R language model". Other packages such as the DerivaGem software that accompanies Hull (1997) publication and that can be found online free of charge are also a good solution for calculating options with CRR lattices.

\section{FROM CASH FLOWS TO A REAL OPTIONS LATTICE}

While the same principles of financial options apply to real options, in this case the underlying asset is an investment project, which as a real asset is not traded in the market and thus does not have its market price determined. Additionally, exercise rules for real options are typically significantly more complex than those for financial options, as they may involve multiple exercise opportunities, combinations of simultaneous distinct option types, and multiple uncertainties.

\section{Market asset disclaimer - MAD}

Given that the underlying real asset, such as an investment project, is not traded in the market, it is impossible to determine its true value and risk-return characteristics. A simple solution to this problem is to assume that the underlying asset is the project itself and that the true market value of the project is the present value $\left(V_{0}\right)$ of the project. This assumption implies that the traditional present value of the project's cash flows without flexibility is the best nonbiased estimator of the market value of the project if it were a traded asset. Copeland and Antikarov (2001) refer to this hypothesis as the market asset disclaimer (MAD). 
The first step in the model is to determine the cash flow structure $F_{t}$ of the project, as shown in equation (3):

$$
F_{t}=\left[R_{t}(1-\gamma)-\lambda_{t}-\Gamma\right](1-\pi)+\lambda_{t}
$$

where $R_{t}$ is the total revenue in year $t ; \gamma$ represents variable costs; $\pi$ is the income tax; $\lambda_{t}$ is the depreciation in year $t$; and $\Gamma$ represents fixed costs. These are projected for a number of years $(n)$, after which we consider a continuation value $(\mathrm{CV})$. The project value at time $t=0$, $V_{o}$, can be determined with equation (4).

$$
V_{0}=\sum_{t=1}^{t=n} \frac{F_{t}}{(1+\mu)^{t}}+\frac{C V_{n}}{(1+\mu)^{n}}
$$

where:

$$
C V_{n}=\frac{F_{n}(1+g)}{(\mu-g)}
$$

$\mu$ is the risk-adjusted discount rate of the project and $g$ is the cash flow perpetuity growth rate.

The purpose is to model the project's value $V$, with the CRR binomial approach, which allows the real options to be exercised by retroactive induction, or backward maximization, maximizing $V$ along the binomial nodes. When the starting point of the lattice is reached, we will have a $V$ increased by the optimal exercise of real options $(\mathrm{RO})$, which we call expanded present value $\left(V 0^{*}\right)$, that is: $V_{o}^{*}=V_{0}+R O$.

\section{Estimating the project's volatility from the income variables}

To model CRR's lattice for a given project, we must estimate the volatility $\sigma_{V}$ of the project value $V$. We assume that the revenue $R_{t}$ is the product of a price and a quantity, where $Q$ is deterministic but the price $\tilde{P}$ is stochastic (indicated by the $\sim$ sign above the variable) with a growth rate of $a$ and volatility $\sigma_{\mathrm{p}}$. The project revenues are described by equation (6).

$$
\tilde{R}_{t}=Q \tilde{P}_{t}
$$

The price $\tilde{P}$ is assumed to follow a geometric Brownian motion (GBM) type of stochastic diffusion process, which can be represented by the differential equation: $d P=\alpha P d t+\sigma_{P} P d z$, where $d z=\varepsilon \sqrt{d t}, \varepsilon \sim N(0,1)$ is the standard Weiner process.

To estimate the two parameters necessary to model this GBM ( $a$ and $\sigma_{\mathrm{P}}$ ), given a historical time series of prices $P_{i}$, with $n$ events, these can be calibrated using the following procedure: first, calculate the log return series of the $(n-1)$ events of the price series with $\operatorname{Ln}\left(P / P_{t-1}\right)$. The growth rate, or drift, $a$ can be estimated by calculating the mean of this log return series, and the volatility parameter $\sigma_{\mathrm{P}}$ by the standard deviation of the same series. These must be in the same time increment, which for project cash flows is in years. If the time series of $P_{t}$ is provided in a different time interval such as monthly, then the values of $a$ and $\sigma_{\mathrm{P}}$ must be converted to yearly values. This is done by multiplying the drift parameter by 12 (12 months per year) and the volatility parameter by $\sqrt{12}$. The values thus obtained can now be used in modeling the GBM for the prices in the process described in equations (8), (9), and (10).

For such a stochastic process, the expected value equation is represented by (7).

$$
P_{t}=P_{o} e^{\alpha\left(t-t_{0}\right)}
$$

The simulation equation is shown in (8):

$$
\tilde{P}_{t}=P_{t-1} e^{\left[\left(\alpha-\sigma_{P}^{2} / 2\right) \Delta t+\sigma_{P} N(0 ; 1)\right]}
$$

where $N(0 ; 1)$ is the normal distribution with mean 0 and standard deviation 1 .

Using the proof of Samuelson (1965) according to whom the return rate of a financial asset will follow a random walk, independently of its future cash flows as long as investors have access to all the asset's information, we assume that $V$ will also follow a GBM process. Therefore, future cash flows dependent on multiple uncertainties, even with autoregressive processes, can be combined into a single multiplicative binomial lattice.

To estimate the volatility of $V$, we use the approach suggested by Copeland and Antikarov (2001), but with the correction made by Brandão, Dyer and Hahn (2012). After estimating the stream of $n$ cash flows with equation (3), and the deterministic initial project value $\bar{V}_{0}$ , we calculate the project value in $t=1$, with equation (9).

$$
\tilde{V}_{1}=\sum_{t=1}^{t=n} \frac{\tilde{F}_{t}}{(1+\mu)^{t-1}}+\frac{C V_{n}}{(1+\mu)^{n}}
$$

As $\tilde{P}$ follows a GBM stochastic process, $\tilde{F}$ and $\tilde{V}$ will also be the result of this GBM diffusion process. We define the variable $\tilde{Z}$ with equation (10):

$$
\tilde{Z}=\operatorname{Ln}\left(\frac{\tilde{V}_{1}}{\bar{V}_{0}}\right)
$$


Running a Monte Carlo simulation (MCS), we use the standard deviation of the variable $\tilde{Z}$ as the volatility of the stochastic project $\left(\sigma_{V}\right)$ value $\tilde{V}$. Note that $\bar{V}_{0}$ is a static value, while $\tilde{V}_{1}$ is stochastic and will have a new value with every simulated trajectory of $\tilde{F}$. The modification of Brandão et al. (2012) to this procedure points that for the MCS on equation (9), it is necessary to attribute a stochastic value from equation (8), only in the first time period $t=1$ of the simulation, with the subsequent increments calculated by the expected value of $P$ from equation (7). Otherwise, the yearly volatility estimate will be overestimated and will monotonically increase with the number of cash flow periods of the project.

\section{CCR lattice applied to real options from cash flow projection}

The lattice structure shown in section "Valuing Derivatives with the CCR Lattice Model" prices options on assets that do not pay dividends or cash flows. In the case of assets such as stocks, ongoing projects, and firms that generate a continuous stream of cash flows to the shareholders, some adjustments must be made.

After estimating the cash flows stream of the project in question, and using equation (9), it is straightforward to calculate the stream of $V_{t}$ values for $t=1$ to $n$, before the subtraction of cash flow at this period $t$, and we call it $V_{\text {ex ante }}$. Consequently, after subtraction of the cash flows $F_{t}$ we will have the stream of $V_{\text {ex post }}$, or the values of the project ex-post cash flows, or dividends. From these, we estimate the stream or vector of dividend yield $\delta_{t}$ from $t=1$ to $n$, as defined in equation (11).

$$
\delta_{t}=F_{t} / V_{t} \text { ex ante }
$$

Using this vector of dividend yield, Copeland and Antikarov (2001) proposed a scheme that builds a project value lattice that incorporates the dividends, or cash flows paid out at each step of the process. At each time step $t$, the values at each node ex ante subtracting of cash flows $\left(V_{a}\right)$ are multiplied by $\left(1-\delta_{i}\right)$, yielding $V_{p}$, or the ex-post project values: $V_{p}=V_{a}\left(1-\delta_{t}\right)$. This model is shown in Figure 3, where the red arrows represent the cash flows subtracted from the project value $V_{a}$ at each time step. The value of the dividends $(D)$ is calculated by equation (12) at every node of the ex-ante values lattice $V_{a}$.

$$
D_{t}=V_{a t} \delta_{t}
$$

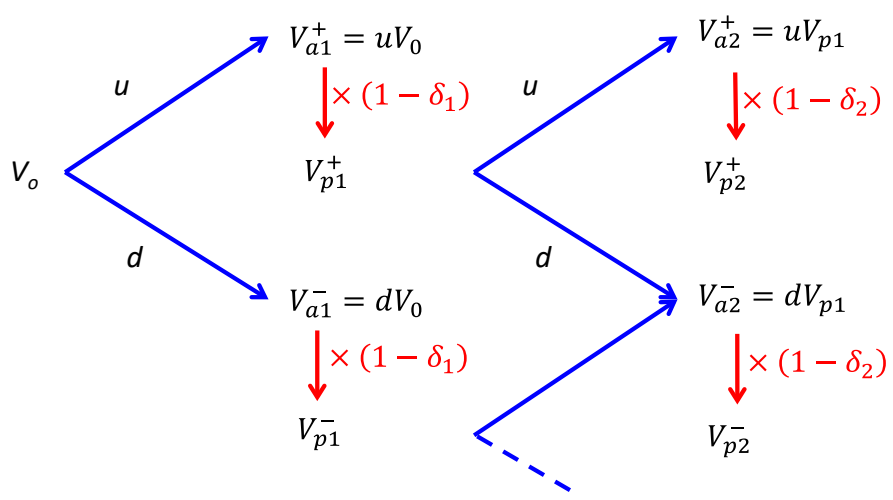

Figure 3. CCR lattice with dividend payment at each node.

This figure presents the values of $V$ ex ante $\left(V_{a}\right)$ and ex post $\left(V_{t}\right)$. The lattice thus 'penalized' by the dividend yields $\delta_{t}$ still is recombining as the one of Figure 1.

As this scheme will produce, at every node, two values (ex ante and ex post), this will yield two lattices (one for values of $V_{a}$ and another for $V_{p}$ ), which are interdependent. As this can encumber the lattice model, we will simplify the above scheme with the model displayed in Figure 4, where the $V_{a}$ lattice is bypassed and only the $V_{p}$ lattice remains, using at each time step the dividend yield $\delta_{t}$ stream, or vector, of the cash flow model to do this.
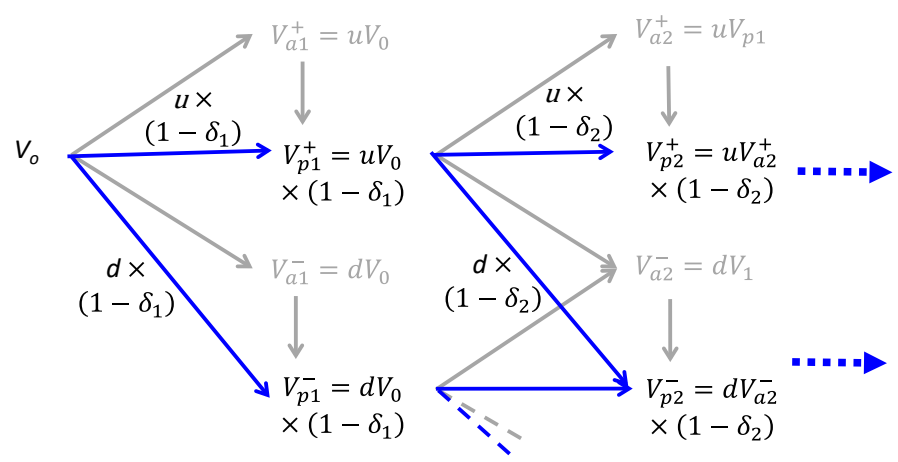

Figure 4. CRR lattice for ex-post values of $V_{p}$.

This lattice, simpler and more straightforward than that of Figure 3, provides all the necessary values for the real options estimation $\left(V_{p}\right)$. Note that this lattice remains recombining.

In Figure 4, the $V_{a}$ values of Figure 3 appear only in light grey and the values of $V_{p}$ are apparent. As stated, our tutorial model uses this approach as it has fewer steps to implement. Yet it brings another complication when discounting the lattice backward from the last step of the model.

At this last step, the real options are exercised on the values of $V p n$, at each node (maximization process) on the 
ex-post values, that is, after the cash flow (dividends) have been paid. At the nodes where the options are exercised, the values of $V p n$ change to $V_{p n}^{\prime}$. As with the normal CCR lattice (without dividends), we move to the previous time period $(n-1)$, and perform the same maximization process at each node, also considering the value of continuation, as also done with the simple CRR lattice in chapter 2 . But this value, previously calculated with equation (10), now uses the ex-ante values $V_{a n}^{\prime}$ of the last step $n$, which is equal to the dividends $D_{n}$ added to $V_{p n}^{\prime}$. And as these dividends are the ones already paid by the project, they are the values of $V_{a n}^{\prime}$ multiplied by $\delta_{n}$. But as the model of Figure 4 has bypassed the estimation of $V_{a}$ lattice, we must use another approach to calculate Dt. We do this using the following algebra: $D_{t}=V_{a t}-V_{p t}=V_{p t} \times \frac{\delta_{t}}{\left(1-\delta_{t}\right)}$. The vectors of values are then calculated with equation (13).

$$
\delta_{t}^{\prime}=\frac{\delta_{t}}{\left(1-\delta_{t}\right)}
$$

which multiplied to $V_{p t}$ yields the dividend values needed to discount the values lattice. Instead of equation (10), the maximization process is the one shown in equation (14).

$\operatorname{maximum}\left[V_{p(t-1)}^{\prime} ;\left(\left[V_{p t}^{\prime+}+V_{p t}^{+} \times \delta_{t}^{\prime}\right] p+\left[V_{p t}^{\prime-}+V_{p t}^{-} \times \delta_{t}^{\prime}\right](1-p)\right) /(1+r)\right](14)$

This discounted process is displayed in Figure 5.

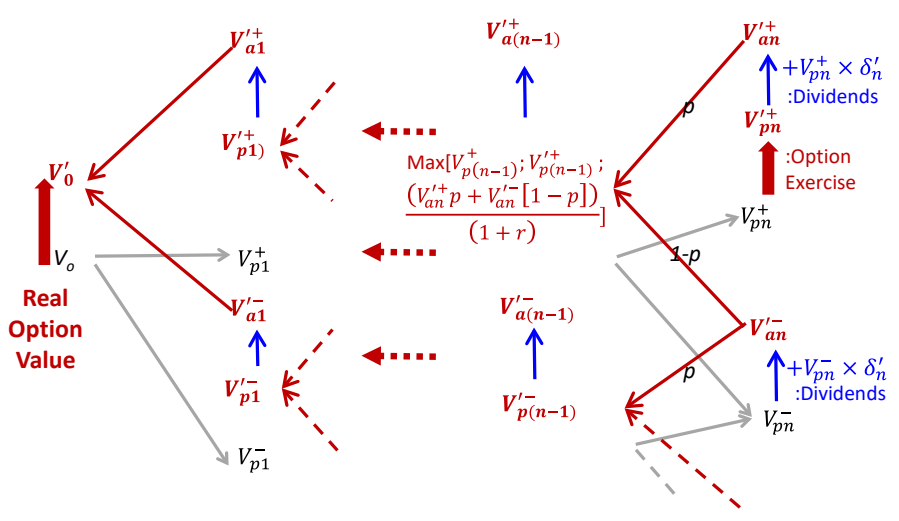

Figure 5. Backward discounting of the lattice for ex-post values of $V_{p}$. Now, as we don't have the values of the ex-ante lattice, we must estimate these by calculating the vector $\delta_{t}^{\prime}$. As shown in Figure 2, starting from the last period $n$ after exercising the options, we move backward at each node adding the value of dividends estimated by $\delta_{n}^{\prime}$, weighting the future values by the risk-neutral probabilities $p$ and $(1-p)$ and discounting with the risk free rate $r$, with equation (14) up to the initial step.
The full understanding of the particulars of the cash flow lattice model shown in this section is relevant for real options researchers and practitioners, as this model is widely used in many real options applications. Several authors have applied this model to infrastructure projects (Garvin \& Cheah, 2004; Iyer \& Sagheer, 2011; Marques, Brandão, \& Gomes, 2019; Oliveira, Couto, \& Pimentel, 2020; Rakić \& Rađenović, 2014), renewable energy (Dalbem, Brandão, \& Gomes, 2014; Santos, Soares, Mendes, \& Ferreira, 2014; Wesseh \& Lin, 2015; Zhang, Zhou, \& Zhou, 2014), mining (Miranda, Brandão, \& Lazo, 2017), and other fields of research.

\section{R LANGUAGE MODEL}

\section{Guidelines for the model routine and numerical example}

In order to assist researchers and practitioners model project cash flows under the real options approach, considering the correct volatility estimation and lattice implementation, we propose an intuitive $\mathrm{R}$ code. In this code, we exemplify the model described in section "From Cash Flows to a Real Options Lattice" through a numerical example.

In this sense, we assume a hypothetical project requiring an initial capital expenditure of $\$ 1.5$ million, which will depreciate in 10 years, which also is the projection horizon of the project $(n)$. In addition, it will have a fixed output $(Q)$ of 10,000 units that will sell at a price $(P)$ assumed today of $100 \$$ /unit, but which is expected to grow at a rate $a$ per year: from $t=1$ to $t=10$.

As we assume that price $(P)$ is the main source of uncertainty in this project, we will treat it as a stochastic variable that follows a GBM, as mentioned in section "From Cash Flows to a Real Options Lattice". Thus, the code first inputs the parameters shown in Table 1 to simulate the price using the Monte Carlo simulation technique. Note that users can change any of these parameters to adapt the code to their project.

Table 1. Price simulation parameters.

\begin{tabular}{ccc}
\hline \multicolumn{3}{c}{ Inputs } \\
\hline $\begin{array}{c}\text { Depreciation duration time } \\
(n)\end{array}$ & $n$ & 10 years \\
Number of time intervals & $i$ & 10 \\
Price growth rate $(a)$ & $a$ & $3 \%$ (per year) \\
Price volatility $\left(\sigma_{p}\right)$ & vol & $15 \%$ (per year) \\
Price at $t=0\left(\mathrm{P}_{0}\right)$ & $P_{0}$ & $\$ 100$ \\
Number of simulations & $n t$ & 10,000 \\
\hline
\end{tabular}

Note. This table presents all the necessary parameters for price simulation. 
This simulation results in a matrix $(X)$ of dimension $n t \times 11$, where the first column represents the prices at $t=0\left(P_{o}=100\right)$ and the other columns the prices simulated at each time point until the tenth year of the project.

After simulating price, the code estimates the project's revenue using equation (6) and assuming a production $(Q)$ of 10,000 units. Then, through equation (3), the code starts the process of calculating the project's cash flows $(F)$, considering fixed costs $(\Gamma)$ of $\$ 300,000$ per year, variable costs $(\gamma)$ of $55 \%$ of the project's income $(R)$, an income tax rate $(\pi)$ of $34 \%$ of EBIT (earnings before interest and taxes), and an annual investment to maintain the project (EI) of $\$ 50,000$. Table 2 summarizes all of these parameters that need to be entered in the code to calculate the cash flows $\left(F_{t}\right)$ and the project value $\left(V_{o}\right)$. As well as the parameters mentioned in Table 1, these can also be changed in the code so that the user can adapt it to the characteristics of their project.

Table 2. Cash flow and project value parameters.

\begin{tabular}{ccc}
\hline & Inputs & \\
\hline Risk-free rate $(\mathrm{r})$ & $\mathrm{r}$ & $6 \%$ (per year) \\
Perpetuity growth rate $(g)$ & $\mathrm{g}$ & $3 \%$ (per year) \\
Discount rate $(\mu)$ & $\mathrm{k}$ & $12 \%$ (per year) \\
Production $(\mathrm{Q})$ & prod & 10,000 units \\
Variable costs $(\gamma)$ & VC & $55 \%$ of revenues \\
Fixed costs $(\Gamma)$ & FC & $\$ 300,000$ \\
Investment & $\mathrm{I}$ & $\$ 1,500,000$ \\
Extra investments & EI & $\$ 50,000$ \\
Income tax $(\pi)$ & IT & $34 \%$ (per year) \\
\hline
\end{tabular}

Note. This table shows all the parameters required to estimate the cash flows and the project value.

As the simulated prices are arranged in a matrix, we need to calculate the cash flow for each year and each price trajectory. In this step, we exclude the first column of the price matrix, because at $t=0$ the project does not generate cash flow. In this way, we will have a cash flow matrix (FCF) of dimensions $n t \times 10$. In addition, since we consider that this project has a continuation value $(C V)$, we have included a column in this matrix that represents the perpetual cash flows of that project. To calculate perpetuity, the code uses equation (5).

Considering a risk-adjusted discount rate of $k=12 \%$ per year, a perpetuity growth rate of $\mathrm{g}=3 \%$ per year, equation (4), and the NPV equation of the package developed by Signorell, Aho, Alfons, Anderegg, Aragon and Arppe (2016), we find that the project value is $V_{o}=\$ 1,661$, yielding a net present value (NPV) of $\$ 161,549$. From this, we can also estimate the dividend yield and, consequently, the present values ex ante and ex post, which allows us to find the variable $\tilde{Z}$, as well as the project volatility $\left(\sigma_{V}\right)$.

Thus, using Monte Carlo simulation as described in section "Estimating the project's volatility from the income variables", the project volatility is estimated as $\sigma_{V}=33 \%$ per year. This value can vary slightly as it is the result of a MCS. Given the volatility of the project, we can determine the parameters of the binomial cash flow tree $(u=1.39, d=0.72$, and $p=0.51)$. With this, the code calculates both the value lattices, using the approach of section "CCR lattice applied to real options from cash flow projection". The value lattices are displayed in Appendix I with both the ex-ante and ex-post values (Figures A1 and A2).

After this, we model two real options on the project lattice. First, an expansion option that is modeled as a call option on the value lattice. It considers that at any time for the next 10 years $(t=1$ to 10$)$ the project value can be augmented by $80 \%$ (multiplied by 1.8 ) at a cost of $\$ 1,200,000$. Second, an abandonment option, modeled as a put option, that considers the project can be sold at a value of its total depreciated investment, minus a discount of $20 \%$.

To incorporate these managerial flexibilities, we need to consider the inputs listed in Table 3. As with the other inputs, these can also be changed so that the code adapts to the project that each user is analyzing.

Table 3. Abandonment and expansion options parameters.

\begin{tabular}{ccc}
\hline & Inputs \\
\hline Abandonment factor & abandf & 0.8 (per year) \\
Expansion factor & expf & 1.8 (per year) \\
Expansion cost & expc & $\$ 1,200,000$ \\
\hline
\end{tabular}

Note. These are the parameters required to calculate the abandonment and expansion options values.

In addition to the inputs mentioned in Table 3, to determine the project value considering the options, we need to find the residual value of the project in case of abandonment. For this, first, we calculate the depreciated asset value each year until year 10 by discounting the depreciation amount from the investments. Then, we multiply these values by the abandonment factor.

Given these parameters, the code calculates the backward discounted lattices for both managerial flexibilities. In summary, following the model of Figure 5, 
the code evaluates backward the maximum value between maintaining, abandoning, and expanding the project each year until year 10. Appendix I also presents these lattices (Figures A3 and A4). At the starting step of this lattice, the project value is now $\$ 2,109,671$, compared to $\$ 1,661,448$ for the project without options. This yields an incremental value of $\$ 448,223$ derived from both expansion and abandonment options.
Finally, the code plots the ex-post dividends lattices with and without options so that we can have a better understanding of the results, as shown in Figure 6.

In addition, we also provide the command to plot the same lattices, but on a log scale. This allows better visualization of the results found, especially the exercise boundaries of the Expansion (Call) and Abandonment (Put) options, as shown in Figure 7.

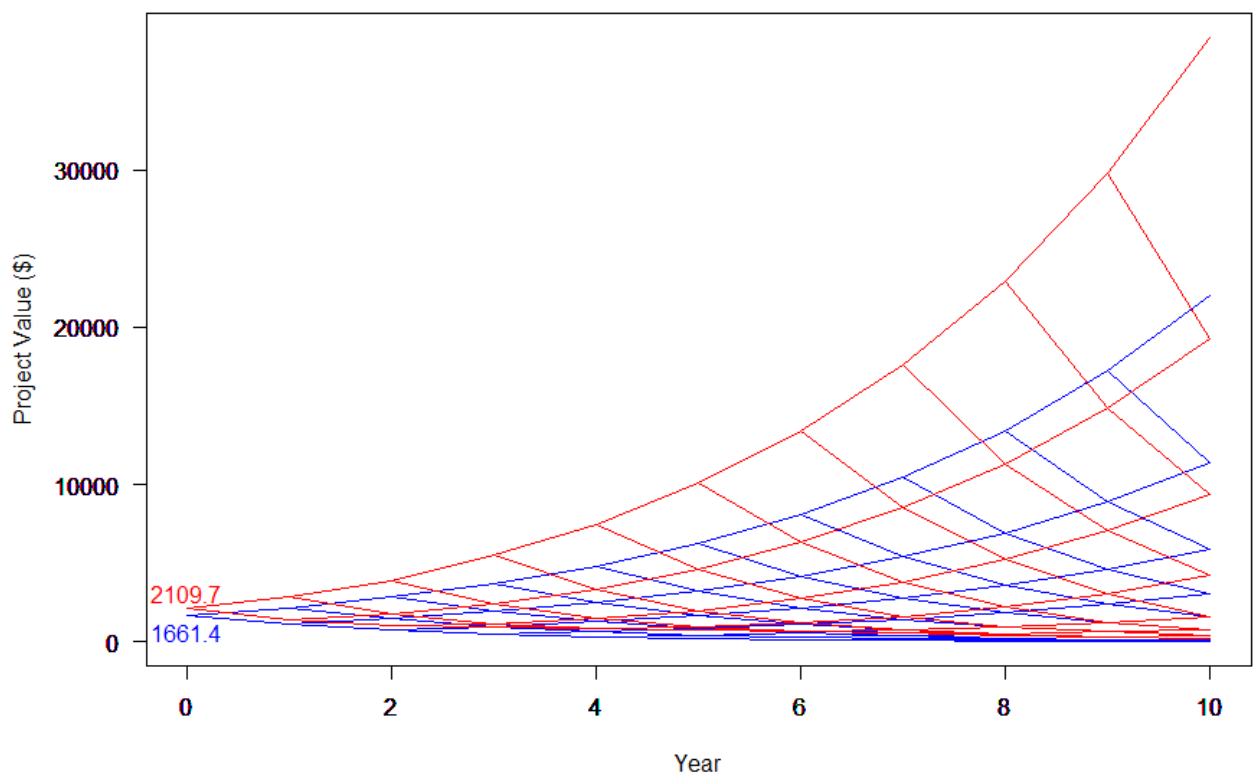

Figure 6. Ex-post lattices with and without abandonment and expansion options.

This figure shows the lattice ex-post dividends considering the abandonment and expansion options $\left(^{*}\right)$ and the lattice ex-post dividends without options $(*)$. The values are in $\$$ thousands.

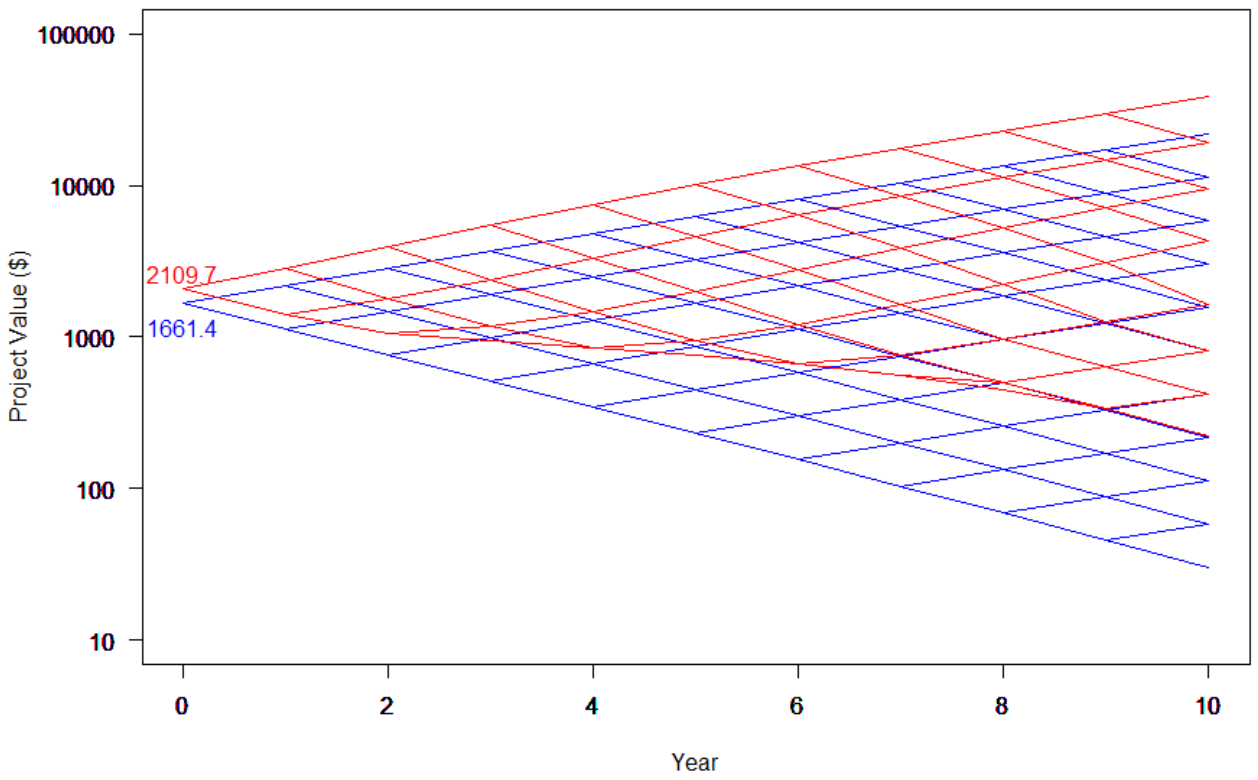

Figure 7. Ex-post lattices with and without abandonment and expansion options in log scale.

This figure shows, in log scale, the lattice ex-post dividends considering the abandonment and expansion options $\left({ }^{*}\right)$ and the lattice ex-post dividends without options $\left(^{*}\right)$. The values are in $\$$ thousands. 


\section{Discussing the proposed code}

The proposed code was built in a very intuitive and simple way so that even beginning researchers can use it in their analysis. However, we believe it is important to provide a general guideline for its correct use. Thus, we draw the reader's attention to a few points. First, the code only models annual cash flows, that is, it only allows the time interval to be equal to $1(d t=1)$. Another point is that only the values listed in Tables 1, 2, and 3 can be changed by the users to adjust them to the reality of the projects they are modeling. To stress this point, the following comment "Parameters: Here, you can change the input values to suit your project" - was included in the appropriate places in the code. Finally, we emphasize that readers should not be concerned if they use the same input values as ours or find output values slightly different from those presented in our article. This variation is common, as the output values are the result of a Monte Carlo simulation.

\section{CONCLUSIONS}

This tutorial provides a guide on the sequence of steps required to implement a real options model, based on the estimation of project cash flows. It presents students, researchers, and practitioners the correct real options procedures to calculate the volatility of a project's value; incorporate the project's cash flows into the CRR binomial model using the cash flow dividend rate; and model the managerial flexibilities (real options) of the project. It uses the Copeland and Antikarov (2001) scheme, incorporating the dividends or cash flows paid out, into a CCR lattice modeling, and is adaptable enough to reproduce a great number of managerial flexibilities available to managers.

We believe this tutorial to be relevant for real options students, researchers, and practitioners, as it contributes to the understanding of project cash flow lattice modeling. It provides a simple and practical method for the pricing of real options that can assist decision-makers to analyze investment opportunities in projects where there is uncertainty and flexibility.

\section{REFERENCES}

Ashuri, B., Kashani, H., Molenaar, K. R., Lee, S., \& Lu, J. (2012). Risk-neutral pricing approach for evaluating BOT highway projects with government minimum revenue guarantee options. Journal of Construction Engineering and Management, 138(4), 545-557. https://doi.org/10.1061/(ASCE)CO.1943-7862.0000447

Bastian-Pinto, C., Brandão, L., \& Hahn, W. J. (2009). Flexibility as a source of value in the production of alternative fuels: The ethanol case. Energy Economics, 31(3), 411-422. https://doi.org/10.1016/j.eneco.2009.02.004

Black, F., \& Scholes, M. (1973). The pricing of options and corporate liabilities. Journal of Political Economy, 81(3), 637-654. Retrieved from https://www.jstor.org/stable/1831029

Brandão, L. E. T., \& Dyer, J. S. (2005). Decision analysis and real options: A discrete time approach to real option valuation. Annals of Operations Research, 135(1), 21-39. https://doi.org/10.1007/s10479-005-6233-9
Brandão, L. E. T., Dyer, J. S., \& Hahn, W. J. (2012). Volatility estimation for stochastic project value models. European Journal of Operational Research, 220(3), 642648. https://doi.org/10.1016/j.ejor.2012.01.059

Copeland, T., \& Antikarov, V. (2001). Real options: A practitioner's guide. New York: Texere Publishing Limited.

Cox, J. C., Ross, S. A., \& Rubinstein, M. (1979). Option pricing: A simplified approach. Journal of Financial Economics, 7(3), 229-263. https://doi.org/10.1016/0304-405X(79)90015-1

Dalbem, M. C., Brandão, L. E. T., \& Gomes, L. L. (2014). Can the regulated market help foster a free market for wind energy in Brazil? Energy Policy, 66, 303-311. http://dx.doi.org/10.1016/j.enpol.2013.11.019

Garvin, M. J., \& Cheah, C. Y. J. (2004). Valuation techniques for infrastructure investment decisions. Construction Management and Economics, 22(4), 373-383. https://doi.org/10.1080/01446190310001649010 
Hull, J. C. (1997). Options, futures and other derivatives. Upper Saddle River, NJ: Prentice-Hall International.

Iyer, K. C., \& Sagheer, M. (2011). A real options based traffic risk mitigation model for build-operatetransfer highway projects in India. Construction Management and Economics, 29(8), 771-779. https://doi.org/10.1080/01446193.2011.597412

Jang, Y.-S., Lee, D.-J., \& Oh, H.-S. (2013). Evaluation of new and renewable energy technologies in Korea using real options. International Journal of Energy Research, 37(13), 16451656. https://doi.org/10.1002/er.2985

Kim, K., Park, H., \& Kim, H. (2017). Real options analysis for renewable energy investment decisions in developing countries. Renewable and Sustainable Energy Reviews, 75, 918-926. https://doi.org/10.1016/j.rser.2016.11.073

Lee, S.-C., \& Shih, L.-H. (2010). Renewable energy policy evaluation using real option model: The case of Taiwan. Energy Economics, 32(s1), S67-S78. https://doi.org/10.1016/j.eneco.2010.04.010

Lin, B., \& Wesseh, P. K., Jr. (2013). Valuing Chinese feed-in tariffs program for solar power generation: A real options analysis. Renewable and Sustainable Energy Reviews, 28, 474-482. https://doi.org/10.1016/j.rser.2013.08.043

Marques, N. L., Brandão, L. E. T., \& Gomes, L. L. (2019). The Rio de Janeiro international airport privatization: A problem of overbidding?. Latin American Business Review, 20(3), 249268. https://doi.org/10.1080/10978526.2019.1624562

Miranda, O., Brandão, L. E., \& Lazo, J. L. (2017). A dynamic model for valuing flexible mining exploration projects under uncertainty. Resources Policy, 52, 393-404. https://doi.org/10.1016/j.resourpol.2017.04.002
Oliveira, A., Couto, G., \& Pimentel, P. (2020). Uncertainty and flexibility in infrastructure investments: Application of real options analysis to the Ponta Delgada airport expansion. Research in Transportation Economics, 100845. https://doi.org/10.1016/j.retrec.2020.100845

Rakić, B., \& Rađenović, T. (2014). Real options methodology in public-private partnership projects valuation. Economic Annals, 59(200), 91-113. https://doi.org/10.2298/EKA1400091R

Samuelson, P. A. (1965). Proof that properly anticipated prices fluctuate randomly. Industrial Management Review, 6(2), 41-49.

Santos, L., Soares, I., Mendes, C., \& Ferreira, P. (2014). Real options versus traditional methods to assess renewable energy projects. Renewable Energy, 68, 588-594. https://doi.org/10.1016/j.renene.2014.01.038

Signorell, A., Aho, K., Alfons, A., Anderegg, N., Aragon, T., \& Arppe, A. (2016). DescTools: Tools for descriptive statistics. $\mathrm{R}$ package version 0.99, 18 .

Wesseh, P. K., Jr., \& Lin, B. (2015). Renewable energy technologies as beacon of cleaner production: A real options valuation analysis for Liberia. Journal of Cleaner Production, 90, 300310. https://doi.org/10.1016/j.jclepro.2014.11.062

Wuertz, D., Setz, T., \& Chalabi, Y. (2017). fOptions: Rmetrics Pricing and Evaluating Basic Options. R package version 3042.86 .

Zhang, M., Zhou, D., \& Zhou, P. (2014). A real option model for renewable energy policy evaluation with application to solar PV power generation in China. Renewable and Sustainable Energy Reviews, 40, 944-955. https://doi.org/10.1016/j.rser.2014.08.021 


\section{Authorship}

\section{Naielly Lopes Marques}

Pontifícia Universidade Católica do Rio de Janeiro, IAG - Escola de Negócios.

Rua Marquês de São Vicente, no. 255, 22451-900, Rio de Janeiro, RJ, Brazil.

E-mail address: naielly.lopes@iag.puc-rio.br

(i) https://orcid.org/0000-0003-1943-9948

\section{Carlos de Lamare Bastian-Pinto}

Pontifícia Universidade Católica do Rio de Janeiro, IAG - Escola de Negócios.

Rua Marquês de São Vicente, no. 255, 22451-900, Rio de Janeiro, RJ, Brazil.

E-mail address: carbastian@gmail.com

(D) https://orcid.org/0000-0001-8074-7662

\section{Luiz Eduardo Teixeira Brandáo*}

Pontifícia Universidade Católica do Rio de Janeiro, IAG - Escola de Negócios.

Rua Marquês de São Vicente, no. 255, 22451-900, Rio de Janeiro, RJ, Brazil.

E-mail address: brandao@iag.puc-rio.br

(D) https://orcid.org/0000-0002-5389-0583

* Corresponding Author

\section{Funding}

The authors thank the Ministério da Ciência, Tecnologia e Inovação, Conselho Nacional de Desenvolvimento Científico e Tecnológico, grants number 303908/2018-1 and 406198/2018-7; and the Fundaçáo Carlos Chagas Filho de Amparo à Pesquisa do Estado do Rio de Janeiro, grant number E-26/202.868/2018, for the financial support.

\section{Conflict of Interests}

The authors have stated that there is no conflict of interest.

\section{Authors' Contributions}

$1^{\text {st }}$ author: conceptualization (lead); methodology (equal); software (lead); validation (lead); writing-original draft (lead); writing-review \& editing (equal).

$2^{\text {nd }}$ author: conceptualization (equal); methodology (lead); writing-original draft (lead); writing-review \& editing (equal).

$3^{\text {rd }}$ author: conceptualization (equal); funding acquisition (lead); methodology (equal); supervision (equal); validation (equal); writing-review \& editing (supporting).

\section{Copyrights}

RAC owns the copyright to this content.

\section{Plagiarism Check}

The RAC maintains the practice of submitting all documents approved for publication to the plagiarism check, using specific tools, e.g.: iThenticate.

\section{Peer Review Method}

This content was evaluated using the double-blind peer review process. The disclosure of the reviewers' information on the first page is made only after concluding the evaluation process, and with the voluntary consent of the respective reviewers.

\section{Data Availability}

All data and materials were made publicly available through the Harvard Dataverse platform and can be accessed at:

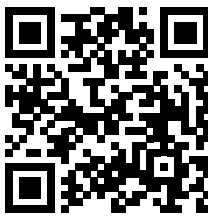

Marques, N. L.; Bastian-Pinto, C.; Brandão, L., 2020, "Replication Data for: A Tutorial for Modeling Real Options Lattices from Project Cash Flows", https://doi.org/10.7910/DVN/YFGIVI, Harvard Dataverse, V1. 


\section{APPENDIX I — PROJECT LATTICES (EX ANTE \& EX POST)}

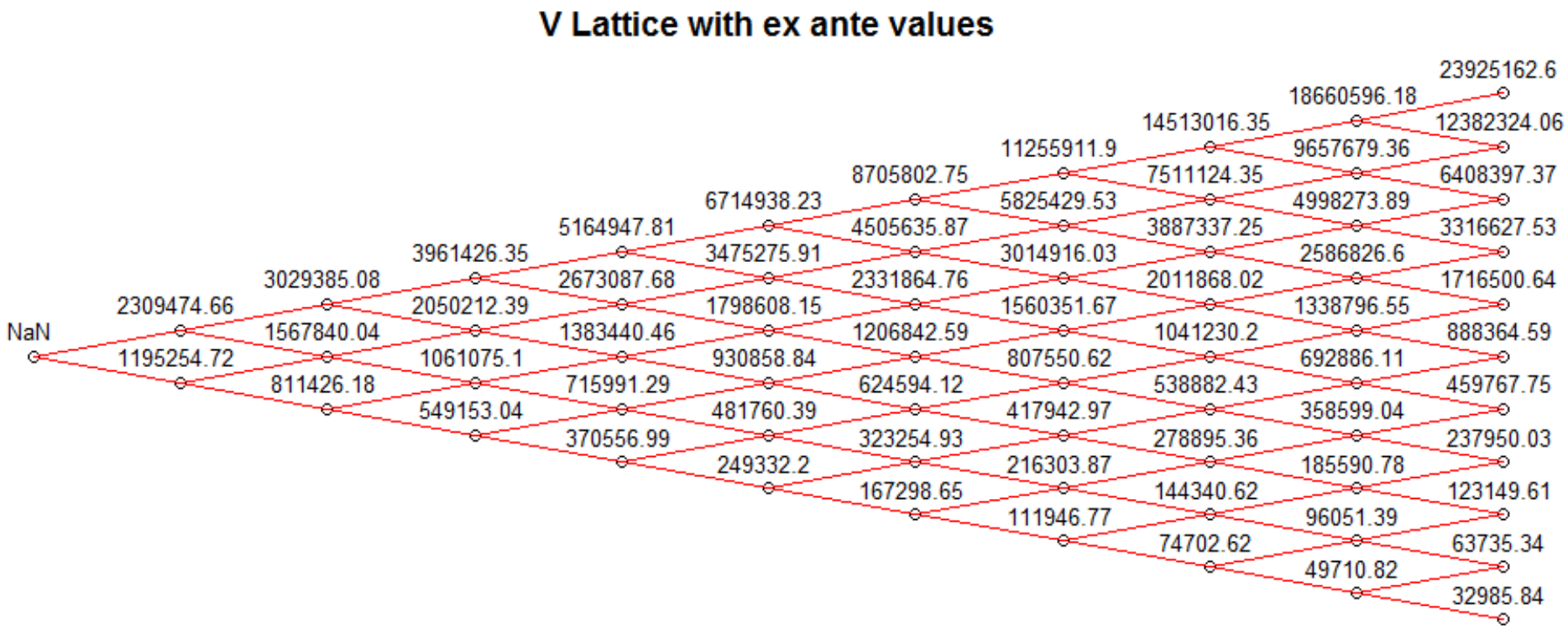

Figure A1. Ex-ante project value lattice.

This is one of the outputs of our R code (Code II) that shows the ex-ante project value lattice. To estimate this, the code uses the approach described in section "CCR lattice applied to real options from cash flow projection". Note that no managerial flexibility was considered in this calculation.

\section{Lattice with ex post values}

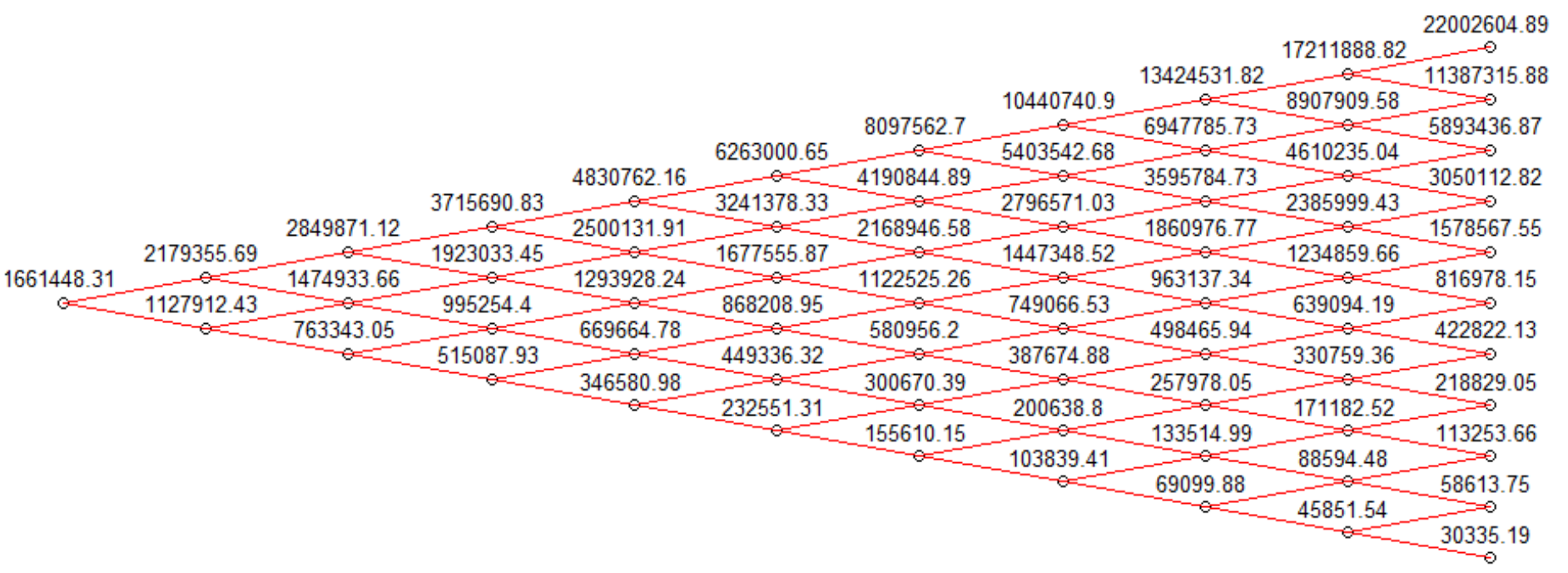

Figure A2. Ex-post project value lattice.

This is one of the outputs of our R code (Code II) that shows the ex-post project value lattice. To estimate this, the code uses the approach described in section "CCR lattice applied to real options from cash flow projection". Note that no managerial flexibility was considered in this calculation. 
Expansion Option: $\quad 80 \% \quad$ expansion, at a cost of: $1,200,000 \$$

Abandonment option: project can be sold at a value of its depreciated investments, minus:

\begin{tabular}{c|c|c|c|c|c|c|c|c|c|c|c|}
\hline $\mathrm{t}=1$ & $\mathrm{t}=2$ & $\mathrm{t}=3$ & $\mathrm{t}=4$ & $\mathrm{t}=5$ & $\mathrm{t}=6$ & $\mathrm{t}=7$ & $\mathrm{t}=8$ & $\mathrm{t}=9$ & $\mathrm{t}=10$ \\
Abandonment value: & $1,120,000$ & $1,036,000$ & 948,000 & 856,000 & 760,000 & 660,000 & 556,000 & 448,000 & 336,000 & 220,000
\end{tabular}

\section{Lattice with ex ante values and exercise of real options}

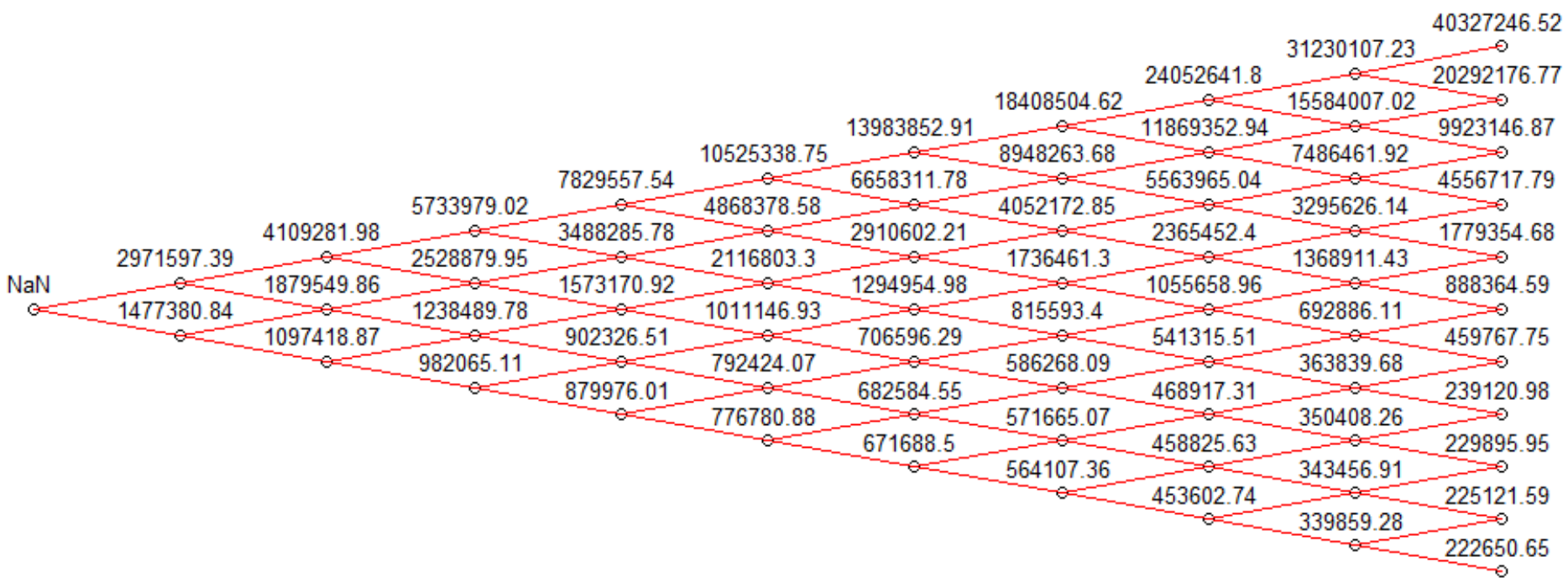

Figure A3. Ex-ante project value lattice with exercise of abandonment and expansion option.

This is one of the outputs of our R code (Code II) that shows the ex-ante project value lattice with exercise of abandonment and expansion options. To estimate this, the code evaluates backward the maximum value between maintaining, abandoning, and expanding the project each year until year 10 .

\section{Lattice with ex post values and exercise of real options}

$\begin{array}{ll}29 & \end{array}$

Figure A4. Ex-post project value lattice with exercise of abandonment and expansion options.

This is one of the outputs of our R code (Code II) that shows the ex-post project value lattice with exercise of abandonment and expansion options. To estimate this, the code evaluates backward the maximum value between maintaining, abandoning, and expanding the project each year until year 10 . 


\section{APPENDIX II - SUMMARY OF VARIABLES USED IN THE R CODE}

Table A1. Variables used in the $\mathrm{R}$ code.

\begin{tabular}{|c|c|}
\hline Description & Variable \\
\hline Time interval & dt \\
\hline Price simulation & $\mathrm{X}$ \\
\hline Revenue & $\mathrm{R}$ \\
\hline Operating revenue & $\mathrm{RO}$ \\
\hline Depreciation $(\chi t)$ & Dep \\
\hline Earnings before interest and taxes & EBIT \\
\hline Free cash flow $\left(F_{t}\right)$ & FCF \\
\hline Perpetuity $(C V)$ & Perp \\
\hline Present value $\left(V_{0}\right)$ & PV \\
\hline Net present value & NPV \\
\hline Ex-ante present value & PVa \\
\hline Ex-post present value & PVp \\
\hline Average present value & PVd \\
\hline Return $(\tilde{Z})$ & IRet \\
\hline Project volatility $\left(\sigma_{V}\right)$ & sig \\
\hline Upside multiplying factor $(\mathrm{u})$ & $\mathrm{u}$ \\
\hline Downside multiplying factor (d) & d \\
\hline Probability (p) & $\mathrm{p}$ \\
\hline Dividend rate & $\operatorname{divr}$ \\
\hline Dividends & $\operatorname{div}$ \\
\hline Ex-ante lattice & Latta \\
\hline Ex-post lattice & Lattp \\
\hline Depreciated asset & Depasset \\
\hline Residual value & Residual \\
\hline Ex-ante lattice with options & Lattao \\
\hline Ex-post lattice with options & Lattpo \\
\hline
\end{tabular}

Note. This table describes all the variables used in the proposed R code (Code II). 